Methods: Multicentre observational study, with retrospective analysis of a prospective cohort, using data from the Portuguese registry of rheumatic diseases - Reuma.pt. Patients with biopsy-proven PLN, MLN and mixed LN were included. Groups were compared using Pearson's Chi-Square for categorical variables and One-Way ANOVA or Kruskal-Wallis for numerical variables. COX regression analysis was used to investigate predictors of CKD (defined as estimated glomerular filtration rate [eGFR] lower than $60 \mathrm{~mL} / \mathrm{min} / 1.73 \mathrm{~m}^{2}$ for at least 3 months) and Kaplan-Meier curves were drawn.

Results: 236 patients were included. Median follow-up was 8 years (IQR 11; maximum 35 years). As seen in table 1, the level of proteinuria did not differ between groups; however, MLN patients presented with significantly lower serum creatinine. Levels of complement C3 and C4 were reduced in PLN but normal in MLN patients, and there were fewer patients with positive anti-dsDNA antibodies in the MLN group $(p<0.001)$. On univariable COX regression, mixed histology was associated with progression to CKD (HR 26 [95\% Cl 3 - 255], p 0.005) (figure 1), however, it lost significance after adjusting for eGFR. In fact, eGFR $\leq 75$ at one year after the renal biopsy (HR 21 [95\% Cl 7 - 65], p<0.001) was the strongest predictor of CKD, even after adjusting for hypertension or histology.

Table 1. Comparative description of the Reuma.pt cohort of patients with proliferative, membranous and mixed LN

\begin{tabular}{lcccc}
\hline & PLN & MLN & Mixed & P \\
\hline Total, N & 186 & 42 & 8 & \\
Females, N (\%) & $157(85)$ & $39(95)$ & $4(50)$ & 0.004 \\
Ethnicity White European, N (\%) & $163(90)$ & $31(78)$ & $7(88)$ & 0.115 \\
\multicolumn{1}{c}{ Other, N (\%) } & $19(10)$ & $9(23)$ & $1(13)$ & \\
Age LN diagnosis(y), median (IQR) & $30(20)$ & $34(16)$ & $42(25)$ & 0.409 \\
SLEDAl at LN diagnosis, median & $16(9)$ & $10(10)$ & $21(17)$ & $0.006^{*}$ \\
(IQR) & & & & \\
uPCR at LN diagnosis, median & $1675(2598)$ & $1698(2153)$ & $2160(3320)$ & 0.629 \\
(IQR) & & & & \\
Creatinine at LN diagnosis, median & $0.80(0.32)$ & $0.70(0.20)$ & $1.00(0.95)$ & $0.006^{*}$ \\
(IQR) & & & & \\
eGFR at LN diagnosis, mean \pm SD & $98 \pm 33$ & $112 \pm 17$ & $82 \pm 45$ & $0.019^{*}$ \\
Albumin at LN diagnosis, mean & $34 \pm 7$ & $34 \pm 7$ & $30 \pm 6$ & 0.390 \\
I SD & & & & \\
C3 at LN diagnosis, mean \pm SD & $0.65 \pm 0.26$ & $0.90 \pm 0.35$ & $0.53 \pm 0.30$ & $<0.001^{\star}$ \\
Positive anti-dsDNA LN diagnosis, & $115(91)$ & $11(48)$ & $6(86)$ & $<0.001^{\star}$ \\
N (\%) & & & & \\
Use of antimalarials, N (\%) & $166(94)$ & $36(92)$ & $8(100)$ & 0.688 \\
Use of immunosuppressants, & $163(94)$ & $33(87)$ & $8(100)$ & 0.245 \\
N (\%) & & & & \\
Use of corticosteroids, N (\%) & $145(84)$ & $33(85)$ & $7(100)$ & 0.511 \\
CKD after LN diagnosis, N (\%) & $27(15)$ & $1(3)$ & $3(38)$ & $0.018^{*}$ \\
ESRD, N (\%) & $7(4)$ & $1(3)$ & $2(25)$ & 0.016 \\
Deaths, N (\%) & $14(8)$ & $2(5)$ & 0 & 0.610 \\
\hline
\end{tabular}

UPCR: urinary protein-creatinine ratio, $\mathrm{mg} / \mathrm{g}$; $\mathrm{y}$ : years; Creatinine presented in $\mathrm{mg} / \mathrm{dL}$, eGFR in $\mathrm{mL} / \mathrm{min} / 1.73 \mathrm{~m}^{2}$, albumin in $\mathrm{g} / \mathrm{L}$ and $\mathrm{C} 3$ in $\mathrm{g} / \mathrm{L}$

Note: Baseline data (LN diagnosis) in grey; other data refer to the course of disease

*Significant difference between the proliferative and membranous groups
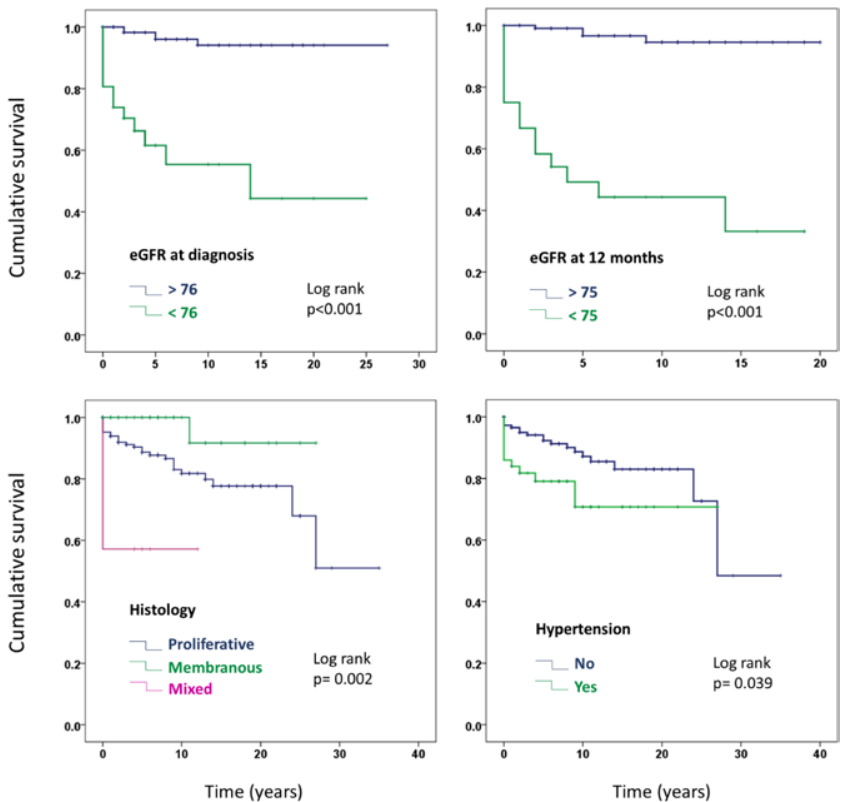

Figure 1. Kaplan-Meir curves showing cumulative survival free of CKD in patients with PLN, MLN and mixed LN
Conclusion: Our results support previous findings from single-centre studies suggesting that MLN has a different serological profile than PLN, possibly reflecting different pathogenesis. Renal function at one year predicts long-term outcome in LN.

Disclosure of Interests: Filipa Farinha: None declared, Sofia C Barreira: None declared, Maura Couto: None declared, Margarida Cunha: None declared, Diogo Fonseca: None declared, Raquel Freitas: None declared, Luís Inês: None declared, Mariana Luis: None declared, Carla Macieira: None declared, Ana Rita Prata: None declared, Joana Rodrigues: None declared, Bernardo Santos: None declared, Rita Pinheiro Torres: None declared, Ruth J. Pepper: None declared Anisur Rahman: None declared, Maria Jose Santos Speakers bureau: Novartis and Pfizer

DOI: 10.1136/annrheumdis-2020-eular.3789

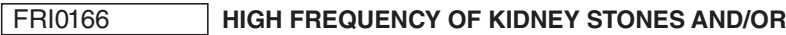 NEPHROCALCINOSIS IN PRIMARY SJOGREN'S SYNDROME MIGHT ACCELERATE CHRONIC RENAL DYSFUNCTION DUE TO TUBULOINTERSTITIAL DISEASE}

Y. Fujisawa $^{1,2}$, Y. Suzuki ${ }^{1}$, T. Zoshima ${ }^{1}$, S. Hara ${ }^{1}$, K. Ito ${ }^{1}$, I. Mizushima ${ }^{1}$, H. Fujii ${ }^{1}$, M. Kawano'. ' Kanazawa University Hospital, Rheumatology, Kanazawa, Japan;

${ }^{2}$ Saiseikai Kanazawa Hospital, Internal Medicine, Kanazawa, Japan

Background: The renal involvement of primary Sjögren's syndrome (pSS) is characterized by distal renal tubular acidosis (RTA), tubulointerstitial nephritis (TIN), and/or glomerulonephritis [1,2]. Kidney stones and nephrocalcinosis are presumably caused by subclinical distal tubular acidosis, but its clinical significance has not been clarified.

Objectives: This study aimed to clarify the frequency and clinical features of patients with pSS with kidney stones and/or nephrocalcinosis.

Methods: We examined 59 patients with anti SS-A/Ro positive pSS who underwent abdominal computed tomography and/or ultrasound between 1998 and 2019 at Kanazawa University Hospital. We identified 2 groups of patients with primary Sjögren's syndrome: 1) patients with kidney stones and/ or nephrocalcinosis (group $A: n=19$ ) and 2) those without kidney stones and/ or nephrocalcinosis (group $B: n=40$ ), and retrospectively analyzed their clinical features.

Results: Kidney stones and/or nephrocalcinosis were confirmed in 19 of 59 $(32 \%)$ patients with pSS. The patients comprised 4 males and 55 females with an average age of 60 years (range, 30 to 83 years) and mean observation period of 96 months (range 1 to 336 months). Estimated glomerular filtration rate (eGFR) at the time of diagnostic imaging (group A vs group $B: 71.5 \mathrm{ml} / \mathrm{min} / 1.73 \mathrm{~m}^{2}$ vs $82.8 \mathrm{ml} / \mathrm{min} / 1.73 \mathrm{~m}^{2} ; \mathrm{p}=0.37$ ) and eGFR at last follow up (group $A$ vs group $B$ : $59.3 \mathrm{ml} / \mathrm{min} / 1.73 \mathrm{~m}^{2}$ vs $74.7 \mathrm{ml} / \mathrm{min} / 1.73 \mathrm{~m}^{2} ; \mathrm{p}=0.03$ ) of group $A$ were lower than those of group $B$ and urinary $\beta 2$-microgloblin (group A vs group B: $7222 \mu \mathrm{g} / \mathrm{mL}$ vs $437 \mu \mathrm{g} / \mathrm{mL} ; p=0.01$ ) and urinary $N$-acetyl- $\beta-D$-glucosaminidase (group $A$ vs group $B: 5.8 \mathrm{U} / \mathrm{L}$ vs $3.9 \mathrm{U} / \mathrm{L} ; \mathrm{p}=0.22$ ) of group $A$ were higher than those of group $\mathrm{B}$, while serum electrolytes (sodium, potassium, chloride, calcium, phosphorus), fractional excretion of calcium (group A vs group B: $1.2 \%$ vs $1.5 \% ; p=0.916$ ), ESS DAI (group A vs group B: 7.6 vs 4.3; $p=0.069$ ), and eGFR decrease rate were not significantly different.

Conclusion: $32 \%$ patients with anti SS-A/Ro positive pSS had kidney stones and/or nephrocalcinosis in our cohort and their presence might accelerate chronic renal dysfunction due to tubulointerstitial disease (subclinical RTA or TIN).

References:

[1] Jain A et al. Renal involvement in primary Sjogren's syndrome: a prospective cohort study. Rheumatol Int 2018; 38: 2251-62.

[2] Jasiek $M$ et al. A multicentre study of 95 biopsy-proven cases of renal disease in primary Sjögren's syndrome. Rheumatology 2017; 56: 362-70.

Acknowledgments: We thank Mr. John Gelblum for critical reading of the manuscript.

Disclosure of Interests: None declared

DOI: 10.1136/annrheumdis-2020-eular.3021

\section{FRI0167 LONG TERM CLINICAL OUTCOME IN SYSTEMIC LUPUS ERYTHEMATOSUS PATIENTS FOLLOWED FOR MORE THAN 20 YEARS IN THREE ITALIAN TERTIARY REFERRAL CENTERS: THE MILAN SYSTEMIC LUPUS ERYTHEMATOSUS CONSORTIUM (SMILE) COHORT}

M. Gerosa ${ }^{1,2}$, G. A. Ramirez $z^{3,4}$, C. Bellocchi ${ }^{1,5}$, L. M. Argolini ${ }^{2}$, L. Moroni ${ }^{3}$, M. Cornalba ${ }^{6}$, N. Farina ${ }^{3}$, L. Dagna ${ }^{3,4}$, R. Caporali, ${ }^{2,6}$, E. Bozzolo ${ }^{3}$, L. Beretta ${ }^{5}$ on behalf of Milan Systemic Lupus Erythematosus Consortium (SMiLE). ${ }^{1}$ Department of Clinical Science and Community Health, University of Milan, Milan, Italy; ${ }^{2}$ Lupus Clinic, Clinical Rheumatology Unit, ASST PINI CTO, Milan, Italy; ${ }^{3}$ IRCCS Ospedale San Raffaele, Unit of Immunology, Rheumatology, 